\title{
A Brief Study on the Mode of Cultivating Students' Critical Thinking in Advanced English Teaching
}

\author{
$\mathrm{Bu}$ Xun \\ English Department, Tianhua College of Shanghai Normal University \\ Shanghai, China
}

\begin{abstract}
In view of the teaching featuring practicality, utilitarianism and absence of critical thinking of the English major in current colleges and universities, this paper summarizes the research results of the predecessors and the core literacy of critical thinking through literature review. Besides, based on the teaching practice of private colleges and universities, this paper constructs a teaching mode of Advanced English focusing on the cultivation of students' critical thinking, that is, complete teaching steps, elaborate teaching design and multidimensional assessment methods, so as to improve students' comprehensive quality and employment competitiveness.
\end{abstract}

Keywords-Critical thinking; Teaching mode; Teaching steps; Teaching design; Assessment methods

\section{INTRODUCTION}

For a long time, English major in colleges and universities in China has been committed to cultivating "applied and interdisciplinary English talents". However, English majors have poor performance in analysis, reasoning and assessment and their weakness is critical thinking. Professor Huang Yuanshen (1998) sharply pointed out such absence of critical thinking: "When students of Department of Foreign Languages encounter arguments and need to reason, when they write articles and need discuss views, when they listen to lectures and need to ask questions, their minds often go blank and they have nothing to say; or if they harbor some vague views, but all are in unorganized way and cannot be uttered explicitly from the very beginning. [2]" "In the curriculum, most of the courses are language skills and language knowledge courses for improving English proficiency and lack the curriculum for improving humanity quality; as to the construction of knowledge structure, skills are preferred over knowledge; for teaching methods, mechanical and mental labor are preferred over discussion and argument favorable for the development of critical thinking and the encouragement of independent thinking. [3]" This view has also been supported by scholars, such as Wen Qiufang (2010), who use logical reasoning or empirical investigation. The phenomenon is particularly prominent in private colleges and universities. In order to achieve differentiated competition, these schools emphasize practicality in terms of talent cultivation and tend to be more utilitarian. However, according to the actual feedback of the employer (Bu Xun, 2017), English majors of private colleges and universities tend to be "unrealistic, weak in learning ability, biased in self-cognition, lack of self-management awareness, and poor performance in application and problem solving."

\section{THE CONNOTATION OF CRITICAL THINLING}

In the 1950s, American educational psychologist Benjamin Bloom divided educational goals into emotional goals, motor skills goals, and cognitive goals. In 1990, Lorin Anderson proposed a six-level model based on the Benjamin Bloom's, from low to high, respectively, it is memorization, understanding, application, analysis, assessment and creation. In the same year, the Delphi project team gave an authoritative definition of critical thinking: "An ideal thinker with critical thinking is accustomed to be diligent and inquisitive, knowledgeable, rational, open-minded, flexible. Besides, he will be impartial in making assessments, honest in the face of personal prejudice, cautious in making judgments, willing to reconsider, clear-minded in the face of problems, organized in handling complicated matters, diligent in searching relevant information, prepared in choosing convincing criteria, concentrated on goals in exploring problems, and consistently ambitious in the most accurate results on the condition of the inquired questions and conditions." Thus, critical thinking includes both cognitive ability (analysis, reasoning, assessment), and emotional traits (curiosity, openness, confidence, uprightness, and determination). It is the unity of the two (Wen Qiufang et al. 2009).

Sun Youzhong (2011) pointed out that "the crucial difference between Western education and Chinese education is that the former puts the cultivation of critical thinking first, while the latter tends to emphasize the systematic mastery of basic knowledge." Taking Yale's English department as an example, it aims to cultivate an author who has a more profound insight into human experience and becomes more robust in writing and a more influential analytical thinker. [5]" And he (2011) also proposed that "To get rid of the current weak position in their university's disciplinary system and improve the employment competitiveness of graduates, foreign language majors must be oriented by the cultivation of students' critical thinking. [5]" The Outline of China's National Plan for Medium and Long-term Education Reform and Development Plan (2010-2020) clearly states that "putting forth efforts to improve students' innovative spirit and practical ability", "advocating a teaching integrating heuristics, inquiry, discussion, and participation so as to help students to learn", "building a sound environment of independent thinking, free exploration, and innovation." It can be seen that the cultivation of critical thinking is still a strategic task related to the national development plan. 


\section{A TEAChING Mode OF AdVANCEd ENGLISH Fucusing ON CRITICAL THINKING}

The Advanced English course is designed for students in the third year of English major. The teaching goal is to further enrich the knowledge, analyze the content of language phenomena, and realize the in-depth exploration of the theme and comparative analysis of culture on the basis of fulfilling the basic skills of the language, so that the cultivation of critical thinking can be included in English teaching. Appreciation of classical texts enables students to appreciate the charm of language, enhance language aesthetics and cultural sensitivity, be good at discovering problems, and use logical and dialectical methods to think deeply and improve their ability to use English comprehensively. The Advanced English teaching mode that includes humanity spirit and critical thinking is mainly reflected in the following aspects:

\section{A. Complete Teaching Steps}

The cultivation of critical thinking is not only reflected in the content of the class, but is included as an indispensable part of the whole process of the lesson. Before class, teachers publish the task list through the online course center, and push the key and difficult problems of the teaching to the students according to the clear teaching objectives, so that students can conduct independent learning before class. Self-directed learning is essentially a psychological relationship between learners and their learning processes and learning content. It is a transcendental and critical thinking, decision-making, and independent action ability (Littlewood 1991). First, students learn by themselves, raise questions, listen to the lesson with questions and they have a clear learning goal. As such, they can listen to the lesson with specific aims. In addition to key words and grammar points, the pre-class tasks of Advanced English mainly include text comprehension, writing strategy analysis, language appreciation assessment, in-depth topic discussion and other high-level cognition covering analysis, reasoning, assessment, and application.

In the classroom, teachers use heuristic questions to stimulate students' curiosity, guide students to think, and conduct summaries. And teachers create an active classroom atmosphere, encourage students to speak out boldly and do PPT displays, cultivate their self-confidence. Also, mind maps or projects presentation from different groups can enable students to listen to different opinions and keep open-minded. Besides, peer reviews and timely feedback from teachers enable students to make self-corrections. What's more, group discussions encourage students to ask questions, challenge authority, pursue truth, and teachers are responsible for answering questions from students.

Post-class learning is the consolidation and extension of the lesson. It is output-oriented and aims to improve students' creative utilization ability in translation and writing. For the content discussed in the class and the student has interest in it, he can consult the relevant literature, conduct thorough consideration, and has the determination and perseverance to pursue his research direction. In this process, teachers play a leading role and serve as students' company. And the teaching is student-oriented and highlights students' dominant position.
The above complete teaching steps not only stress students' cognitive ability, but also cultivate students' emotional characteristics, so that they can learn independently before class, study cooperatively in class, and learn profoundly after class, thus becoming a man good at analysis, thinking, and argument.

\section{B. Elaborate Teaching Design}

For the cultivation of critical thinking, only the pre-, in-, and post-teaching steps are not enough. Teachers also need to adopt advanced teaching methods to provide students with rich teaching resources and design various teaching activities so as to improve students' learning interest and class participation.

First of all, teachers should keep pace with the times, make full use of the advantages of modern educational technology, adopt hybrid teaching, establish an online learning platform, and create an environment for independent learning, thereby mobilizing students' enthusiasm and stimulating their motivation for learning. Teachers upload a variety of supplementary teaching materials to the resource section of the online course center and mobile APP, which is convenient for students to view and download anytime and anywhere, improves the utilization rate of student's fragmentation time. And teachers can check student's homework completion degree and track students' learning process, and collect teaching feedback in real time.

For the choice of supplementary teaching materials, teachers mainly consider the following factors: 1) The diversity of viewpoints. Teachers will choose corpus from different media, similar or opposite to the author's point of view, so that students can hear different voices, respect different opinions, and compare and explain them. 2) Cross-cultural sensitivity. For language points involving cultural phenomena, teachers will supplement the cultural background knowledge of China and the West, and let students discuss and perform comparative analyses. 3) The length and difficulty of the content. The chosen corpus should be short and concise with refined contents. It is interesting and easy to understand, and the time should not be too long. 4) The diversity of forms. The supplementary materials include classic readings from famous masterpieces, audios and videos selected from domestic and foreign teaching websites and media, such as TED lectures, as well as small papers downloaded from academic websites, and micro-courses created by teachers using recording software etc. The supplementary materials are presented in various forms and have rich contents, which are available for students to choose freely. With clear learning objectives, students can make their own decisions to determine learning content and schedule and this is a key ability to learn independently.

After the supplementation of teaching resources, how to use the resources to organize teaching activities and design teaching tasks is the key to Advanced English teaching. Taking the narrative "A Class Act" relating to teacher-student relationship as an example, teachers assign different tasks to six groups of students before class. The tasks are making electronic stories, drawing plot maps, tracking mood changes, conducting character analysis, rewriting the end and doing the performance, and writing in different perspectives respectively 
(teachers have uploaded the relevant micro-course videos to the online course center for students to learn by themselves before class, provide office answering time and answer students' questions in time after they complete the task themselves). Making electronic stories is to let students adopt a top-down text analysis method so as to understand the meaning and structure of the article; drawing plot maps is to encourage students to visualize their thinking, and to select key events that promote the development of the plot; tracking mood changes is to let students learn to appreciate language and analyze rhetorical techniques, thus improving their language aesthetics and literary appreciation and enabling students to apply them consciously in the future writing; conducting character analysis is to encourage students to deeply explore the characters, see them through dialogues, actions, and psychological activities, analyze the rationality and intrinsic motivation of their behavior, and conclude the character's personality; rewriting the end and doing role play stimulate students' imagination and creativity and provide them with a stage for their self expressions (it turns out that many students are veteran actors); and rewriting in different perspectives is to encourage students to flexibly change their viewpoints and think in all-round directions. In the classroom, each group presents their tasks in turn. Teachers encourage groups to conduct peer assessments and affirm the completion of the tasks, positively strengthen the highlights in the presentations, and give timely feedback and constructive suggestions for improvement.

In this process, students' cognitive skills have been comprehensively exercised, including content understanding, text analysis, plot hypothesis, logical reasoning, language appreciation, feature summaries, and involving clarity, relevance, logic, profundity and flexibility. All these are the cognitive criteria that constitute the second level of critical thinking (Wen Qiufang, 2009). At the same time, many classmates dare to speak in class, love to read after class, are studious and good at asking questions, respect different ideas. As a result, their emotional characteristics are developed, emotional appeals are satisfied, because classroom presentations and speeches enhance students' self-confidence; the end rewriting and role play give full play to students' creativity and bring them a sense of accomplishment; their favorite contents and meaningful knowledge learning gives students great satisfaction and enhances their motivation for learning in the future.

\section{Multidimensional Assessment Methods}

Course assessment is an important means to assess the performance of teachers' teaching and students' learning. The examination serves as an indicator of students' learning. The traditional assessment methods are mostly summative assessments, focusing on the mastery of listening, vocabulary, grammar and reading comprehension skills. Such methods neither encourage students to take tests actively nor highlight the critical thinking of the test content, ignoring students' learning process, and evaluating students just by a test paper.

Advanced English adopts rich and diverse assessment methods, increases the proportion of subjective tests, reduces the weight of summative assessment, and adopts a formative assessment mechanism. Liu Jianda divides the relationship between assessment and learning into three categories, and respectively they are assessment of learning, assessment for learning and assessment as learning. Formative assessment not only checks how much students learn, but also tracks students' learning process and assesses their progress. In this way, assessment and learning help each other. Ultimately, assessment is one of the ways to improve students' ability to think.

Multidimensional assessment methods include testing individual students as well as group work, such as research projects and classroom presentations. The scoring of group work promotes students' participation. Clear scoring standards are set up and the scoring is obtained via the mutual assessments among groups. Test forms include both the written test and the online test of the course center, as well as one-toone interviews between teachers and students. The interviews aim to examine students' understanding of the lesson' theme and the experience of extracurricular reading. Besides, objective questions of traditional vocabulary and reading comprehension, the content of the written test include subjective questions relating to rhetorical methods, translation comparison, error correction and essay writing, encouraging students to give open answers in combination with their own understanding and explain their opinions rationally and reasonably. Students' assessment introduces curve grading, which considers not only students' grades in the class, but also their vertical progress in the learning process. Through the establishment of the portfolio, students' work assignments are collected, their learning process is tracked, students are encouraged to reflect and their self-confidence and sense of accomplishment are cultivated. Diversified assessment methods include interactions between teachers and students, between students, and between students and network technology. There are also intra-group cooperation, group competition. The methods are in various forms, greatly mobilizing students' enthusiasm and participation. As such, the goal of critical thinking cultivation can be realized.

\section{SUMMARY}

The cultivation of critical thinking not only relates to the reform of colleges and universities, but also reflects China's long-term development strategy. If English majors want to avoid being marginalized in their disciplines, they must emphasize the cultivation of critical thinking in teaching, improve the quality of talent training, and enhance their employment competitiveness, so as to achieve the sustainability of professional development. Advanced English teaching uses complete teaching steps, hybrid advanced teaching methods, well-designed multiple teaching activities and diverse assessment methods. This highlights the cultivation of students' critical thinking and realizes the teaching reform so as to provide qualified talents for China. 


\section{REFERENCES}

[1] Cai Jigang. On the Reorientation of College English Teaching in China [J]. Foreign Language Teaching and Research, 2010, (4): 306-308.

[2] Huang Yuanshen. Absence of Critical Thinking [J]. Foreign Languages and Their Teaching, 1998, (7): 1,19.

[3] Huang Yuanshen. Courses for English Major Must be Thoroughly Reformed--Talking About "Absence of Critical Thinking" [J]. Foreign Language World, 2010, (1): 11-16.

[4] Li Liwen. Writing Assessment Model Design for English Major: Oriented by the Cultivation of Critical Thinking [J]. Foreign Languages and Their Teaching, 2011, (1): 31-35.

[5] Sun Youzhong. Highlighting the Cultivation of Critical Thinking and Developing In-depth Teaching for English major [J]. Foreign Languages in China, 2011, (3): 49-58.

[6] Wen Qiufang, Wang Jianqing, Zhao Cairan, Liu Yanping, Wang Haimei. Constructing the Theoretical Framework for the Measuring Tools of Critical Thinking of College Students in Foreign Languages [J]. Foreign Language World, 2009, (1): 37-43. 